\title{
Exkursion zur Straßburger Luther-Ausstellung
}

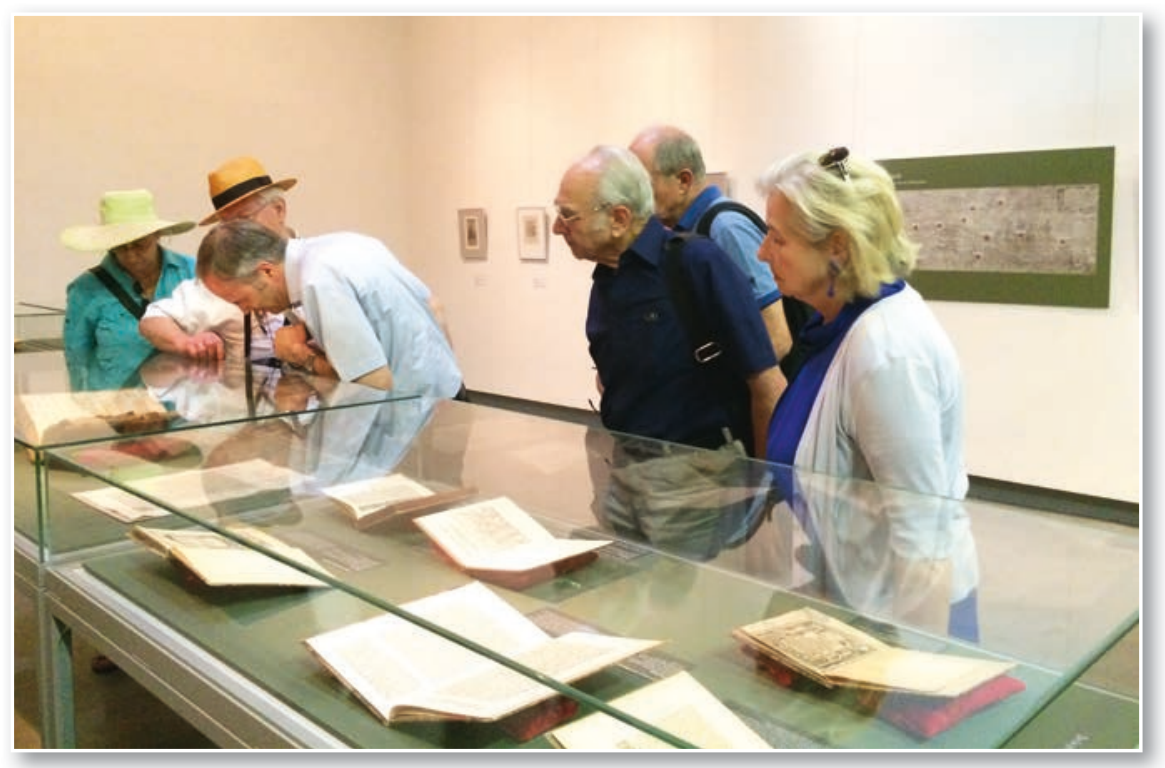

dem Verlauf und den Anliegen der Reformation hin.

Bei einem gemeinsamen Mittagessen erwies sich das Elsass als auch in kulinarischer Hinsicht gelungene Mischung französischer und deutscher Einflüsse. Die anschließende Zeit zur freien Verfügung nutzten viele zu einer Besichtigung der Kathedrale und der Altstadt. Die meisten nahmen dann an einer Führung durch die BNU teil, die von Frau Régine Sutter in deutscher Sprache übernommen wurde. Dabei beeindruckten die ansprechende Gestal-

Rund zwanzig Personen beteiligten sich im Juli 2017 an einer Exkursion der Württembergischen Bibliotheksgesellschaft zur Luther-Ausstellung der BNU Strasbourg. Herr Herrmann erläuterte als Mit-Kurator der WLB das spezifische Profil der Ausstellung mit ihren regionalen und thematischen Schwerpunkten. Besonderes Interesse fanden Illustrationen, Einbände sowie das mit vielen Exponaten aus Stuttgart bestückte Segment zum Bibeldruck. Zahlreiche Rückfragen aus der Gruppe deuteten auf eine intensive Beschäftigung mit tung, die effektive technische Ausstattung wie auch das architektonische Zueinander historischer und innovativer Elemente in der Partnerbibliothek der WLB. Die bautechnische Entwicklung und die Struktur des Bestandes der BNU wurden deutlich bei der Besichtigung verschiedener Abschnitte des Magazins und der Räume für Dauer- und Wechselausstellungen.

Die Exkursions-Gruppe kehrte mit vielen Eindrücken und Anregungen am Abend nach Stuttgart zurück.

\section{Christian Herrmann}

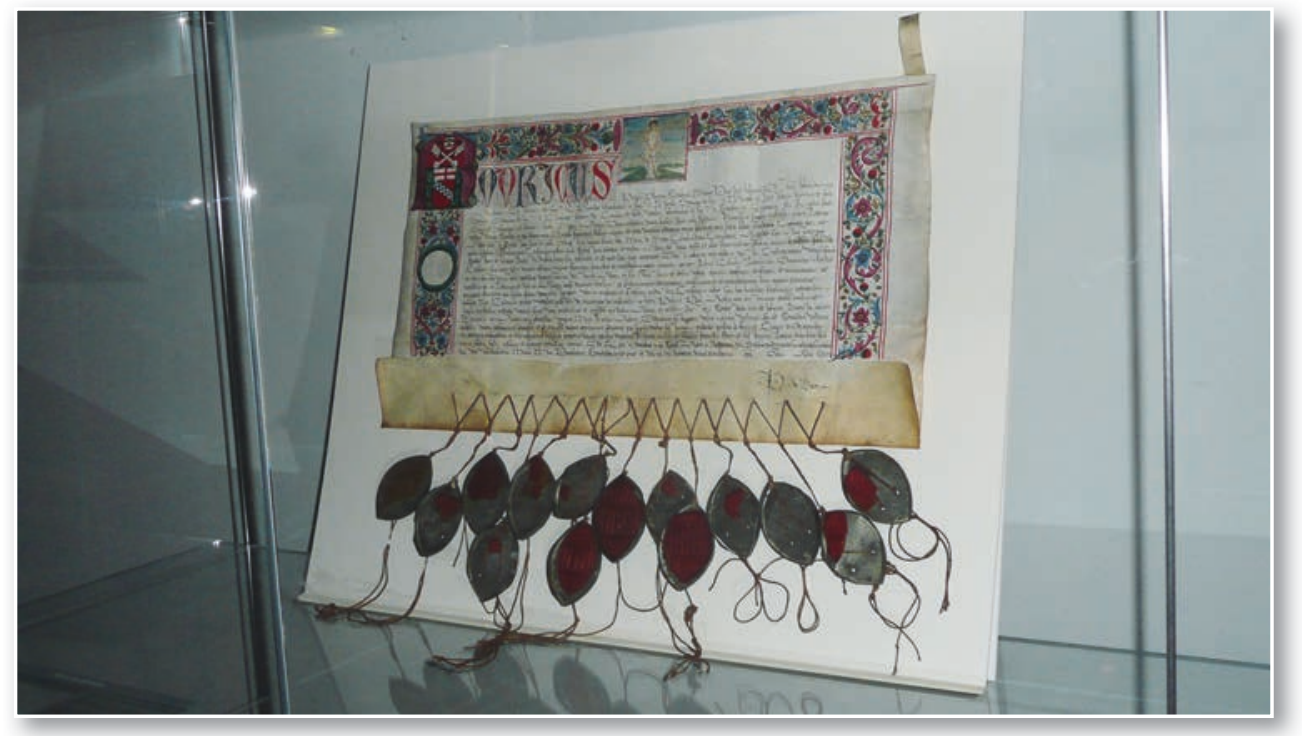

